\title{
Textured $\mathrm{Pb}$-doped $\mathrm{Bi}-2212$ superconductors for current limiters
}

A. Sotelo ${ }^{1}$, Sh. Rasekh ${ }^{1}$, H. Amaveda ${ }^{1}$, P. Bosque ${ }^{2}$, M. A. Torres ${ }^{1}$, M. A. Madre $^{1}$, J. C. Diez ${ }^{1}$

${ }^{1}$ Instituto de Ciencia de Materiales de Aragón (ICMA) (CSIC-Universidad de Zaragoza), C/M ${ }^{a}$ de Luna, 350018 Zaragoza. Spain

${ }^{2}$ Centro Universitario de la Defensa de Zaragoza. Academia General Militar. Ctra. de Huesca s/n. 50090-Zaragoza (Spain).

\begin{abstract}
$\mathrm{Bi}_{2-x} \mathrm{~Pb}_{x} \mathrm{Sr}_{2} \mathrm{CaCu}_{2} \mathrm{O}_{y}(\mathrm{x}=0.0,0.3,0.4$, and 0.5$)$ textured materials have been prepared by the laser floating zone technique. The E-I curves showed and increase of the slope of the normal to superconducting transition with $\mathrm{Pb}$ addition. The best values have been obtained for the $0.4 \mathrm{~Pb}$ doped samples, around 16 at $77 \mathrm{~K}$. In spite of this improvement, $\mathrm{Pb}$ addition decreased $J_{C}$ and $T_{C}$ in all cases. On the other hand, electrical characterization at lower temperatures has led to an impressive raise in the $0.4 \mathrm{~Pb}$ doped samples, reaching $n$ values around 31 , and $J_{C}$ of about $3000 \mathrm{~A} / \mathrm{cm}^{2}$, at $65 \mathrm{~K}$. At the same time, the mechanical integrity of the vitreous precursor materials has been determined. All the obtained results clearly indicate that these precursors when properly processed by the laser floating technique are promising candidates for practical applications as current limiters.
\end{abstract}

Keywords: Grain growth; Bi-2212; Doping; Platelets; Electrical properties

Corresponding author: A. Sotelo, asotelo@unizar.es; Tel: +34 976762617; Fax: +34976761957 


\section{Introduction}

Since the discovery of superconductivity in the Bi-Sr-Ca-Cu-O system $[1,2]$, many works have been performed in the development of practical applications of these materials. As it is well known, applications such as current leads or current limiters should involve high electrical carrying capacity [3]. Different strategies have been used in order to obtain high-performance superconducting materials, as synthesis methods [4], doping [5], and texturing [6]. Among all these approaches, the production of highly oriented superconducting grains has been shown as the most adequate for carrying high current densities at $77 \mathrm{~K}$ $[7,8]$. Among all the High- $T_{C}$ superconductors, $\mathrm{Bi}_{2} \mathrm{Sr}_{2} \mathrm{CaCu}_{2} \mathrm{O}_{8+\delta}(\mathrm{Bi}-2212)$ materials have demonstrated that they are suitable for many applications when they are properly processed in order to obtain a good grain alignment $[9,10]$. A established technique for rapidly produce well textured BSCCO rods from a melt is the Laser Floating Zone (LFZ) method, as reported in previous works [11-14]. The microstructure of the superconducting materials is characterized by a good alignment of the grains, with their $a-b$ planes quasi-parallel to the growth direction $[15,16]$. This high degree of texture leads to a very important increase of the transport properties, as $J_{C}$, due to the reduction of the number of low-angle junctions [17].

One of the drawbacks found in the $\mathrm{Bi}-2212$ superconducting materials is the low slope of the superconducting to normal transition on the electrical current curve, E-I. This characteristic imposes severe limitations for its application as fault current limiters. The usual solution to overcome this problem is based on the use of samples with long lengths. Another possible way is the cationic substitution, which could introduce effective flux pinning centers and increase the slope of the E-I curves [18]. The partial substitution of Bi by $\mathrm{Pb}$ has shown to be useful to increase the intragranular pinning properties in single crystals, leading to the enhancement of both irreversibility field and critical current density $[19,20]$. In some studies, Pb substitution for Bi has decreased the anisotropy of the $\mathrm{Bi}-2212$ phase at high temperatures [21]. These $\mathrm{Pb}$-doped crystals are composed by two alternating $\mathrm{Bi}(\mathrm{Pb})-2212$ phases ( $\alpha$ and $\beta$ ) with different $\mathrm{Pb}$ content [22]. The a phase exhibits a modulated structure with a nominal $\mathrm{Pb}$ content around 0.4 , while the $\beta$ one is a modulation-free structure and has higher $\mathrm{Pb}$ content, about 0.6 [22]. The interfaces between these two 
phases are extended planar defects, which can act as strong flux pinning centers [22]. The best pinning properties in this $\mathrm{Pb}$-doped system can be found in the combination of a dominant $\beta$ phase strengthened by $\alpha / \beta$ interfaces [20]. This optimal phase combination has been obtained for an effective $\mathrm{Pb}$ substitution of 0.33 [20]. These promising results obtained in single crystals have not been successfully achieved in polycrystalline systems, as bulk and tapes, with this doping [23-26].

The aim of this work is to study the influence of $\mathrm{Pb}$ doping on the transport properties of $\mathrm{Bi}-2212$ superconducting materials produced by the laser floating zone technique. The cylindrical precursors for the LFZ were produced by a melt quenching technique which allows the rapid and simple production of long vitreous cylinders with high dimensional homogeneity. In order to study the mechanical integrity of these rapidly quenched materials, a mechanical characterization has been performed (flexural strength). On the other hand, the sharpness of the superconducting to normal transition of the E-I curves (using the power law $E \sim I^{n}$ ), were determined in the textured samples in order to study their applicability as fault current limiters.

\section{Experimental}

Vitreous cylinders with nominal $\mathrm{Bi}_{2-x} \mathrm{~Pb}_{x} \mathrm{Sr}_{2} \mathrm{CaCu}_{2} \mathrm{O}_{y}$ composition ( $\mathrm{x}=0.0,0.3$, 0.4 , and 0.5) were prepared from $\mathrm{Bi}_{2} \mathrm{O}_{3}$ (98\%, Panreac), $\mathrm{PbO}$ (99\%, Panreac), $\mathrm{SrCO}_{3}\left(98+\%\right.$, Panreac), $\mathrm{CaCO}_{3}$ (98.5\%, Panreac) and $\mathrm{CuO}$ (98\%, Panreac) commercial powders. They were weighed in the appropriate proportions, mixed and ball-milled for 30 minutes at $300 \mathrm{rpm}$ in acetone media. The resulting slurry was then dried under infrared radiation and thermally treated at 750 and $800^{\circ} \mathrm{C}$ for $12 \mathrm{~h}$, with an intermediate manual milling, in order to decompose the carbonates before the melting process, as reported in previous works [27]. The prereacted mixture was subsequently placed in a Pt crucible at temperatures between 1050 and $1100^{\circ} \mathrm{C}$ during at least $1 \mathrm{~h}$ in order to get a homogeneous melt. The liquid was then introduced in a silica tube $(2 \mathrm{~mm}$ internal diameter and $250 \mathrm{~mm}$ length) using a vacuum pump, producing a rapid solidification inside the tube which leads to the formation of vitreous cylindrical precursors as described in detail in [28]. These precursors were mechanically characterized using three point bending tests in a Instron 5565 machine with a $10 \mathrm{~mm}$ loading 
span fixture and a punch displacement speed of $30 \mu \mathrm{m} / \mathrm{min}$. The data obtained have been evaluated through the Weibull distribution to determine the reproducibility of the samples. Moreover, SEM micrographs of the fractured surfaces were recorded in a JEOL 6000 SEM microscope, and associated with their respective mechanical properties.

The vitreous cylinders were also used as feed in a LFZ system [29] to produce textured ceramic rods. The texturing process has been performed using a continuous power (CW) Nd:YAG laser $(\lambda=1064 \mathrm{~nm})$ in air atmosphere, with a growth rate of $30 \mathrm{~mm} / \mathrm{h}$. Moreover, the seed was rotated clockwise at $15 \mathrm{rpm}$ in order to maintain the thermal and compositional homogeneity of the molten zone while the seed was rotated anticlockwise at $3 \mathrm{rpm}$ to keep the cylindrical shape in the textured materials. In these growth conditions, it has been found that adjusting the laser power output to obtain a stable molten zone between 11.5 times the rod diameter, the solidification front can be stabilised to produce homogeneous textured cylinders.

As it is well known, Bi-2212 superconducting ceramics present an incongruent melting, producing a number of secondary phases upon solidification (as Bi$\left.2201, \mathrm{CaCuO}_{2}, \mathrm{Sr}_{1-\mathrm{x}} \mathrm{Ca}_{\mathrm{x}} \mathrm{CuO}_{2}, \ldots\right)[30,31]$. As a consequence, it is necessary to perform a thermal treatment in order to produce the $\mathrm{Bi}-2212$ phase from the secondary ones. This process was performed in air atmosphere and consisted in two consecutive steps. The first step was fixed in $60 \mathrm{~h}$ at temperatures ranging between 835 and $850^{\circ} \mathrm{C}$ due to the fact that previous studies have shown that the best properties for the $0.4 \mathrm{~Pb}$ samples were obtained in previous works at $835^{\circ} \mathrm{C}$ [32]. Furthermore, $850^{\circ} \mathrm{C}$ has been chosen as the upper temperature limit as for the higher $\mathrm{Pb}$-doped samples, an important amount of liquid phase is produced [33]. In this step, the Bi-2212 phase is produced by the reaction between the different secondary phases. The second step consisted in $12 \mathrm{~h}$ at $800^{\circ} \mathrm{C}$, in order to adjust the oxygen content in the superconducting phase and maximize its electrical properties, followed by a quench to room temperature in air. Before these thermal treatments, the samples were cut with the adequate dimensions ( $4 \mathrm{~cm}$ long) and Ag contacts were painted for the electrical measurements. After the thermal procedure these contacts have typical resistance values below $1 \mu \Omega$. 
Microstructural characterization was performed on polished longitudinal crosssections of samples in a scanning electron microscope (JEOL 6000 SEM) equipped with an energy dispersive spectroscopy (EDS) system. Electrical characterization was performed using the standard four-probe configuration. Resistivity as a function of temperature, from 77 to $300 \mathrm{~K}$, was measured using a $d c$ current of $1 \mathrm{~mA}$, in order to determine the transport $T_{C}$ values. Transport critical current density $\left(J_{C}\right)$ values were determined at $77 \mathrm{~K}$ using the $1 \mu \mathrm{V} / \mathrm{cm}$ criterion. Moreover, $J_{C}$ values of the undoped, 0.3 , and $0.4 \mathrm{~Pb}$ doped samples, have been determined between 65 and $77 \mathrm{~K}$ by pumping liquid nitrogen [24]. From the $E-I$ curves, the variation of the slope of the normal to superconducting state as a function of temperature was determined using the power law $E \sim I^{n}$ in the transition region.

\section{Results and discusion}

\subsection{Vitreous materials characterization}

The mechanical characterization of the different $\mathrm{Pb}$-doped samples has been performed in at least 75 samples for each composition. The mean maximum stress $\left(\sigma_{\max }\right)$ together with their standard errors, are displayed in Table I. As it can be observed from these data, the $\sigma_{\max }$ tends to decrease when the amount of $\mathrm{Pb}$ is raised. Moreover, the dispersion of results (evaluated as the standard error) increase in all $\mathrm{Pb}$ doped samples, compared with the undoped ones. Furthermore, with all the obtained data a Weibull distribution has been made for each composition following the procedure described in [34]. In Fig. 1, the Weibull plot for the undoped samples is displayed as a representative example, and the obtained $m$ values for the different samples are shown in Table I. As it can be easily deduced from these data, the samples reproducibility is increased when the $\mathrm{Pb}$ content is raised, as indicated by the Weibull parameter. In order to explain the scattering of these data, fractographical studies were performed on the fractured surfaces of the samples. In Fig. 2, typical and representative fractures corresponding to low (a), mean (b) and high (c) strength Bi-2212 undoped samples are displayed. From these images, it can be deduced that the presence of small porosity (indicated by \#1 in Fig. 2a) produced during the solidification decreases the three point bending strength of these samples 
(usually below $100 \mathrm{MPa}$ ). This is due to the reduction of the effective cross section of these samples induced by the presence of porosity. In the case of samples with $\sigma$ values around the mean ones (between 100 and $200 \mathrm{MPa}$ ), no defects have been identified in the fractographical study (see Fig. 2b). On the other hand, the highest strength has been obtained in samples which present small precipitates (typically cuprate phases, indicated by \#2 in Fig. 2c) close to the region where the crack begins. This effect is due to the deflection produced by these precipitates on the crack propagation, leading to very high strength (over $200 \mathrm{MPa}$ ).

\subsection{Textured and annealed materials characterization}

After the growth processes, the samples were annealed at different temperatures between 835 and $850^{\circ} \mathrm{C}$. It has been found that some samples were molten down at temperatures $>840^{\circ} \mathrm{C}$ due to an excessive liquid phase formation during the annealing process. Moreover, electrical characterization has shown that $0.5 \mathrm{~Pb}$ doped samples were not superconducting at $77 \mathrm{~K}$. As a consequence, only the results obtained at the annealing temperature of $835^{\circ} \mathrm{C}$ will be discussed in the following paragraphs.

The typical microstructure obtained in all the samples after annealing is presented in Fig. 3, where representative longitudinal polished sections are shown. From these micrographs, it can be easily seen that undoped samples possess nearly $\mathrm{Bi}(\mathrm{Pb})-2212$ single phase (grey contrast, \#1 in Fig. 3a). Moreover, the $\mathrm{Bi}(\mathrm{Pb})-2212$ grains are well aligned with respect to the growth direction. On the other hand, $0.3 \mathrm{~Pb}$ addition increases the amount of secondary phases, as $\mathrm{Bi}(\mathrm{Pb})-2201$ (light grey contrast, \#2 in Fig. 3b), and $(\mathrm{Sr}, \mathrm{Ca}) \mathrm{CuO}_{2}$ (black contrast, \#3 in Fig. 3b). Further Pb substitution leads to the formation of a new phase, the $(\mathrm{Sr}, \mathrm{Ca}){ }_{14} \mathrm{Cu}_{24} \mathrm{O}_{41}(14: 24$, dark grey contrast, \#4 in Fig.3c), clear indication that the equilibrium conditions in the solidification front have been modified by $\mathrm{Pb}$. Moreover, $\mathrm{Pb}$ doping also affects the grain orientation producing an increased misalignment when $\mathrm{Pb}$ amount is raised. EDS analysis performed on several grains in each $\mathrm{Pb}$-doped sample has shown that the amount of $\mathrm{Pb}$ incorporated in the $\mathrm{Bi}-2212$ crystal structure is lower than the nominal $\mathrm{Pb}$ content, with mean contents of around $0.26,0.34$, and 0.3 for the $0.3,0.4$, and $0.5 \mathrm{~Pb}$ doped samples, respectively. This effect can be 
explained by the $\mathrm{Pb}$ content found in the $\mathrm{Bi}(\mathrm{Pb})-2201$ secondary phase, which is slightly higher than the nominal one. Moreover, the decrease in $\mathrm{Pb}$ content in the $\mathrm{Bi}-2212$ phase for the $0.5 \mathrm{~Pb}$-doped samples is due to the formation of $\mathrm{Pb}$ and Bi-rich phases with variable compositions and $(\mathrm{Bi}, \mathrm{Pb}):(\mathrm{Sr}, \mathrm{Ca}): \mathrm{Cu}$ cation relationships ranging between 3:4:1 and 4:5:1 [32,35].

Transport resistivity measurements have shown that undoped samples possess a $T_{C}$ of $88.1 \mathrm{~K}$. When $\mathrm{Pb}$ is added, a decrease on the $T_{C}$ values to 81.0, 82.2, and $81.0 \mathrm{~K}$, for the $0.3,0.4$, and $0.5 \mathrm{~Pb}$-doped samples, respectively, are obtained. From these values, it is clear that $0.4 \mathrm{~Pb}$ doped samples possess slightly higher critical temperatures than the other doped ones, probably due to its $\mathrm{Pb}$ content, closer to the $\alpha$ phase found in previous works [22]. Moreover, the relatively low $T_{C}$ found for the undoped samples is due to the low annealing temperature, compared with the one used in other works for this kind of polycrystalline bulk ceramics [36].

The same microstructural features affecting the $T_{C}$ values on the samples are playing a crucial role on the transport $I_{C}$. From the E-I curves measured at $77 \mathrm{~K}$, the $I_{C}$ values were determined to be around $23,8,7$, and $3 \mathrm{~A}$ for the undoped and $0.3,0.4$, and $0.5 \mathrm{~Pb}$ doped samples, respectively. From these data, it is clear that $\mathrm{Pb}$ addition leads to an important decrease on the critical intensity. Moreover, among the $\mathrm{Pb}$ doped samples the very important loss of grain alignment in the $0.5 \mathrm{~Pb}$ doped ones is the responsible for the drastic fall of $I_{C}$, compared with the other $\mathrm{Pb}$ doped materials. On the other hand, when considering the samples section (around $1.4 \mathrm{~mm}$ diameter in all cases), $J_{C}$ reaches values of about $1500 \mathrm{~A} / \mathrm{cm}^{2}$ for the undoped samples, decreasing when $\mathrm{Pb}$ doping is raised to 550,500 , and $200 \mathrm{~A} / \mathrm{cm}^{2}$ for the $0.3,0.4$, and 0.5 $\mathrm{Pb}$ doped samples, respectively.

On the other hand, as reported in previous works [32], transport $J_{C}$ dramatically increases when temperature is decreased below $77 \mathrm{~K}$. As a consequence, the $J_{C}$ values for the best samples (undoped, 0.3 , and $0.4 \mathrm{~Pb}$ doped samples) were determined between 77 and $65 \mathrm{~K}$ and displayed in Fig. 4. As it can be observed in the graph, critical current density increases linearly in all cases when temperature is decreased. Moreover, the slope of these lines is much higher for the pure samples than for both $\mathrm{Pb}$-doped ones due to the best microstructure found in the pure samples. On the other hand, it can be also observed that the 
slope for the $0.4 \mathrm{~Pb}$ doped samples is slightly higher than for the $0.3 \mathrm{~Pb}$ doped ones, leading to very similar critical current values at low temperatures $(\sim 3000$ $\mathrm{A} / \mathrm{cm}^{2}$ at $\left.65 \mathrm{~K}\right)$.

The obtained $J_{C}$ values of the different samples as a function of their slope for the normal to superconducting state transition, between 77 and $64 \mathrm{~K}$, is illustrated in Fig. 5. As it can be clearly seen in the graph, in spite of their lower $J_{C}$ values, the $\mathrm{Pb}$ doped samples show higher $\mathrm{n}$ values than the undoped ones. Moreover, for the $0.4 \mathrm{~Pb}$ doped samples the raise of the $\mathrm{n}$ values is much higher than the obtained for the $0.3 \mathrm{~Pb}$ doped one, probably due to its $\mathrm{Pb}$ content in the $\mathrm{Bi}-2212$ phase which is closer to the $\alpha$ phase found in previous works [22] than in the case of the nominal 0.3 Pb doped ones. Furthermore, these very high $n$ values, together with the relatively high $J_{C}$ values (around 31 , and $3000 \mathrm{~A} / \mathrm{cm}^{2}$ at $65 \mathrm{~K}$, respectively) at low temperatures, are very promising in order to apply these $\mathrm{Pb}$ doped materials as current limiters at temperatures well below $77 \mathrm{~K}$.

\section{Conclusions}

$\mathrm{Bi}_{2-x} \mathrm{~Pb}_{\mathrm{x}} \mathrm{Sr}_{2} \mathrm{CaCu}_{2} \mathrm{O}_{\mathrm{y}}(\mathrm{x}=0.0,0.3,0.4$, and 0.5$)$ vitreous ceramics were fabricated from the melt. In spite of the decrease of the mechanical properties of these glasses due to $\mathrm{Pb}$ doping, Webull statistics have shown an increase on the results reproducibility when $\mathrm{Pb}$ content is raised. After texturing and annealing these glasses, it has been found that increasing $\mathrm{Pb}$ content, the alignment of grains is decreased, leading to nearly total grain misalignment for samples with $0.5 \mathrm{~Pb}$ content. These microstructural features are reflected in the electrical properties, decreasing $T_{C}$ and $J_{C}$ with $\mathrm{Pb}$ doping. Despite of this decrease on the transport electrical properties, $\mathrm{Pb}$ addition has been shown to increase, in a very important manner, the slope of the normal to superconducting transition, reaching values much higher than the usually obtained in this kind of materials, together with attractive critical current densities at temperatures below $77 \mathrm{~K}$.

\section{Acknowledgements}

The authors wish to thank the Gobierno de Aragón (Research Groups T12 and T87) for financial support. The authors also acknowledge the Spanish MINECOFEDER (Projects MAT2011-22719 and MAT2013-46505-C3-1-R) for funding. 
The technical contributions of C. Estepa and C. Gallego are also acknowledged. Sh. Rasekh acknowledges a JAE-PreDoc2010 grant from CSIC. Authors would like to acknowledge the use of Servicio General de Apoyo a la InvestigaciónSAI, Universidad de Zaragoza. 


\section{References}

1. Michel, C., Hervieu, M., Borel, M. M., Grandin, A., Deslandes, F., Provost, J., Raveau, B.: Z. Phys. B 68, 421 (1987)

2. Maeda, H., Tanaka, Y., Fukutomi, M., Asano, T.: Jpn. J. Appl. Phys. 27, L209 (1988)

3. Chen, M., Donzel, L., Lakner, M., Paul, W.: J. Eur. Ceram. Soc. 24, 1815 (2004)

4. De la Fuente, G. F., Sotelo, A., Huang, Y., Ruiz, M.T., Badia, A., Angurel, L. A., Lera, F., Navarro, R., Rillo, C., Ibañez, R., Beltran, D., Sapiña, F., Beltran,

A.: Physica C 185-189, 509 (1991)

5. Sotelo, A., Madre, M. A., Diez, J. C., Rasekh, Sh., Angurel, L. A., Martinez,

E.: Supercond. Sci. Technol. 22, 034012 (2009)

6. De la Fuente, G. F., Ruiz, M. T., Sotelo, A., Larrea, A., Navarro, R.: Mater. Sci. Eng. A 173, 201 (1993)

7. Qu, T.-M., Han, Z., Flükiger, R.: Physica C 444, 71 (2006)

8. Huang, Y., de la Fuente, G. F., Sotelo, A., Badia, A., Lera, F., Navarro, R., Rillo, C., Ibañez, R., Beltran, D., Sapiña, F., Beltran, A.: Physica C 185-189, 2401 (1991)

9. Hermann, P. F.: Handbook of Applied Superconductivity. IOP Publishing, Bristol (1998)

10. Noe, M., Juengst, K. P., Werfel, F. N., Elschner, S., Bock, J., Breuer, F., Kreutz, R.: IEEE Trans. Appl. Supercond. 13, 1976 (2003)

11. Vieira, J. M., Silva, R. A., Silva, R. F., Costa, F. M.: Appl. Surface Sci. 258, 9175 (2012)

12. Mora, M., Sotelo, A., Amaveda, H., Madre, M. A., Diez, J. C., Angurel, L. A., de la Fuente, G. F.: Bol. Soc. Esp. Ceram. V. 44, 199 (2005)

13. Feigelson, R. S., Gazit, D., Fork, D. K., Geballe, T. H.: Science 240, 1642 (1988)

14. Mora, M., Sotelo, A., Amaveda, H., Madre, M. A., Diez, J. C., Capel, F., López-Cepero, J. M.: J. Eur. Ceram. Soc. 27, 3959 (2007)

15. Ozkurt, B., Madre, M. A., Sotelo, A., Yakinci, M. E., Ozcelik, B.: J.

Supercond. Nov. Magn. 25, 799 (2012)

16. Costa, F. M., Rasekh, S., Ferreira, N. M., Sotelo, A., Diez, J. C., Madre, M. A.: J. Supercond. Nov. Magn. 26, 943 (2013) 
17. Shi, D.: High temperature superconducting materials science and engineering. Pergamon Press, Oxford (1995)

18. Sotelo, A., Mora, M., Madre, M. A., Amaveda, H., Diez, J. C., Angurel, L. A., Mayoral, M. C.: Bol. Soc. Esp. Ceram. V. 45, 228 (2006)

19. Chong, I., Hiroi, Z., Izumi, M., Shimoyama, J., Nakayama, Y., Kishio, K., Terashima, T., Bando, Y., Takano, M.: Science 276, 770 (1997)

20. Musolino, N., Bals, S., van Tendeloo, C., Clayton, N., Walker, E., Flukiger, R.: Physica C 399, 1 (2003)

21. Motohashi, T., Nakayama, Y., Fujita, T., Kitazawa, K., Shimoyama, J., Kishio, K.: Phys. Rev. B 59, 14080 (1999)

22. Hiroi, Z., Chong, I., Takano, M.: J. Solid State Chem. 138, 98 (1998)

23. Miao, H., Kitaguchi, H., Kumakura, H., Togano, K.: Physica C 298, 312 (1998)

24. Madre, M. A., Amaveda, H., Mora, M., Sotelo, A., Angurel, L. A., Diez, J. C.: Bol. Soc. Esp. Ceram. V. 47, 148 (2008)

25. Crossley, A., Caplin, A. D., Berenov, A. V., MacManus-Driscoll, J. L.:

Supercond. Sci. Technol. 13, 551 (2000)

26. Funahashi, R., Matsubara, I., Ueno, K., Mizuno, K.: Physica C 315, 247 (1999)

27. Carrasco, M. F., Costa, F. M., Silva, R. F., Gimeno, F., Sotelo, A., Mora, M., Diez, J. C., Angurel, L. A.: Physica C 415, 163 (2004)

28. Sotelo, A., Rasekh, Sh., Madre, M. A., Diez, J. C.: J. Supercond. Nov. Magn. 24, 19 (2011)

29. Angurel, L. A., Diez, J. C., de la Fuente, G. F., Gimeno, F., Lera, F., LopezGascon, C., Martinez, E., Mora, M., Navarro, R., Sotelo, A., Andres, N., Recuero, S., Arroyo, M. P.: Phys. Status Solidi A 203, 2931 (2006)

30. Carrasco, M. F., Silva, R. A., Silva, N. J. O., Silva, R. F., Vieira, J. M., Costa, F. M.: Appl. Surf. Sci. 255, 5503 (2009)

31. Sotelo, A., Madre, M. A., Rasekh, Sh., Diez, J. C., Angurel, L. A.: Adv. Appl. Ceram. 108, 285 (2009)

32. Sotelo, A., Rasekh, Sh., Constantinescu, G., Amaveda, H., Torres, M. A., Madre, M. A., Diez, J. C.: J. Eur. Ceram. Soc.

10.1016/j.jeurceramsoc.2014.04.010

33. Majewski, P.: Supercond. Sci. Technol. 10, 453 (1997) 
34. ASTM standard C 1239-00

35. Sotelo, A., Majewski, P., Park, H. S., Aldinger, F.: Physica C 272, 115 (1996)

36. Sotelo, A., Madre, M. A., Rasekh, Sh., Constantinescu, G., Torres, M. A., Diez, J. C.: J. Supercond. Nov. Magn. 26, 985 (2013) 
Table I. Mechanical (mean $\sigma_{\max }$, its standard error, and Weibull coefficient, $\mathrm{m}$ ) properties of vitreous samples as a function of $\mathrm{Pb}$ content.

\begin{tabular}{|l|c|c|c|}
\hline Sample & $\sigma_{\max }(\mathbf{M P a})$ & Standard error & $\boldsymbol{m}$ \\
\hline $\mathbf{0 . 0} \mathbf{P b}$ & 140.8 & 4.7 & 2.9 \\
\hline $\mathbf{0 . 3} \mathbf{P b}$ & 132.3 & 9.6 & 3.1 \\
\hline $\mathbf{0 . 4} \mathbf{P b}$ & 136.0 & 6.4 & 3.7 \\
\hline $\mathbf{0 . 5} \mathbf{~ P b}$ & 121.1 & 7.3 & 3.8 \\
\hline
\end{tabular}




\section{Figure captions}

Figure 1. Weibull distribution for the undoped $\mathrm{Bi}-2212$ glass ceramics.

Figure 2. SEM micrographs or representative fractured surfaces for samples with a) low; b) medium; and c) high three point bending strength. \#1 indicates porosity, and \#2 a cuprate secondary phase precipitated in the solidification.

Figure 3. SEM micrographs of representative longitudinal polished sections of the different $\mathrm{Bi}_{2-x} \mathrm{~Pb}_{x} \mathrm{Sr}_{2} \mathrm{CaCu}_{2} \mathrm{O}_{x}$ samples after annealing, for $\mathrm{x}=\mathrm{a}$ ) 0.0; b) 0.3; c) 0.4 ; and d) 0.5 . \#1 indicates the $\mathrm{Bi}(\mathrm{Pb})-2212$ phase (grey contrast); $\# 2$ the $\mathrm{Bi}(\mathrm{Pb})-2201$ one (light grey contrast); $\# 3$ the $(\mathrm{Sr}, \mathrm{Ca}) \mathrm{CuO}_{2}$ (black contrast); and $\# 4$ the $(\mathrm{Sr}, \mathrm{Ca}){ }_{14} \mathrm{Cu}_{24} \mathrm{O}_{41}$ (dark grey contrast).

Figure 4. Tranport $J_{C}$ vs. temperature, for $\mathrm{Bi}_{2-x} \mathrm{~Pb}_{x} \mathrm{Sr}_{2} \mathrm{CaCu}_{2} \mathrm{O}_{y}$ textured samples after annealing, for $\mathrm{x}=0.0 \bullet ; 0.3 \boxminus$; and $0.4 \diamond$.

Figure 5. Evolution of $\mathrm{n}$ values with the transport critical current density, for $\mathrm{Bi}_{2}$ ${ }_{x} \mathrm{~Pb}_{\mathrm{x}} \mathrm{Sr}_{2} \mathrm{CaCu}_{2} \mathrm{O}_{y}$ textured samples after annealing, for $\mathrm{x}=0.0 \bullet ; 0.3 \mathrm{\square}$; and 0.4 $\diamond$. 
Figure 1

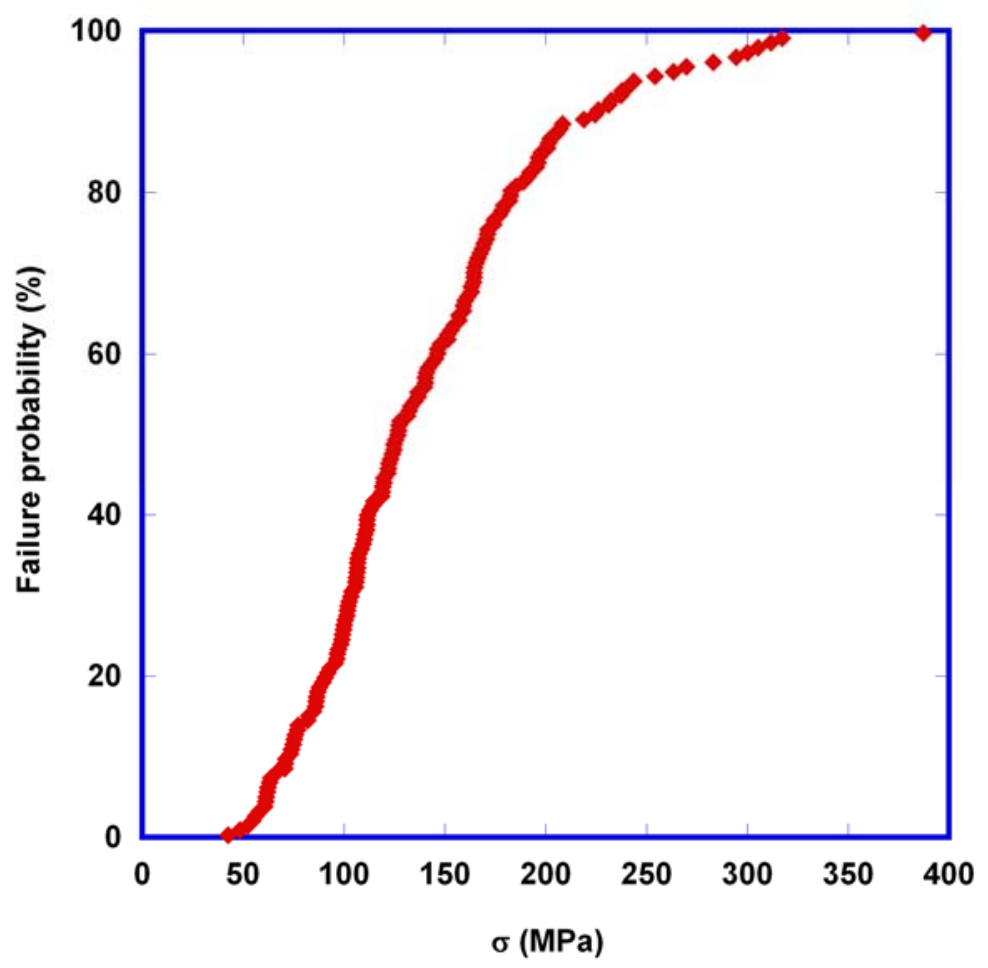


Figure 2
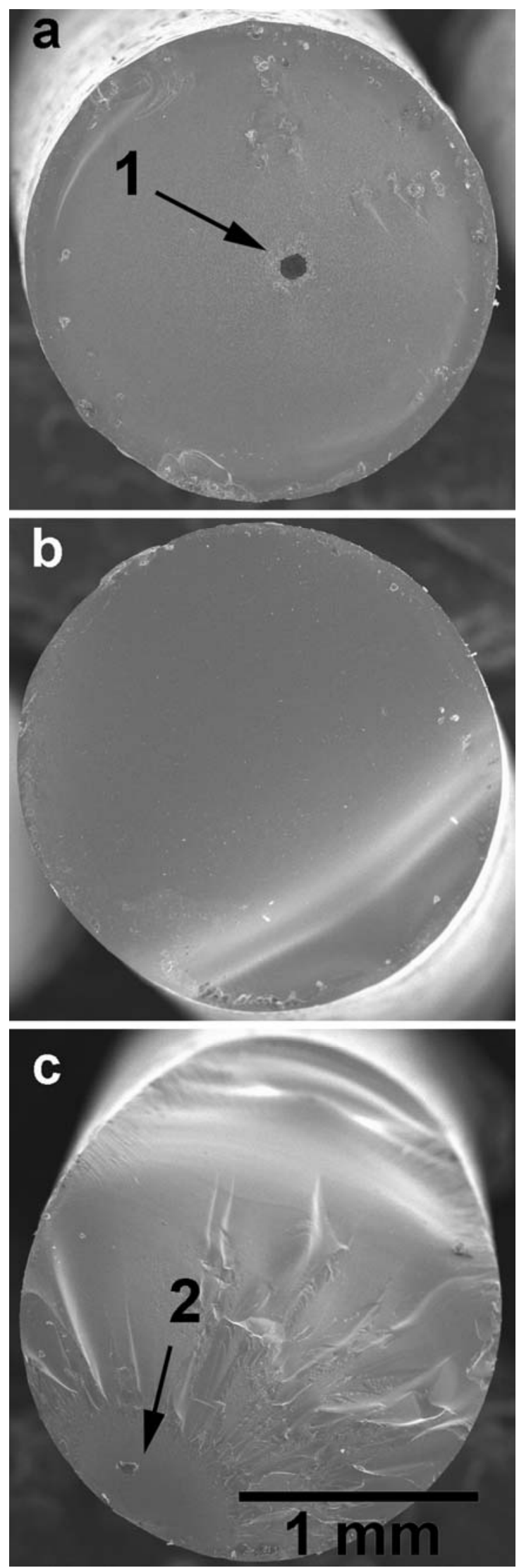
Figure 3

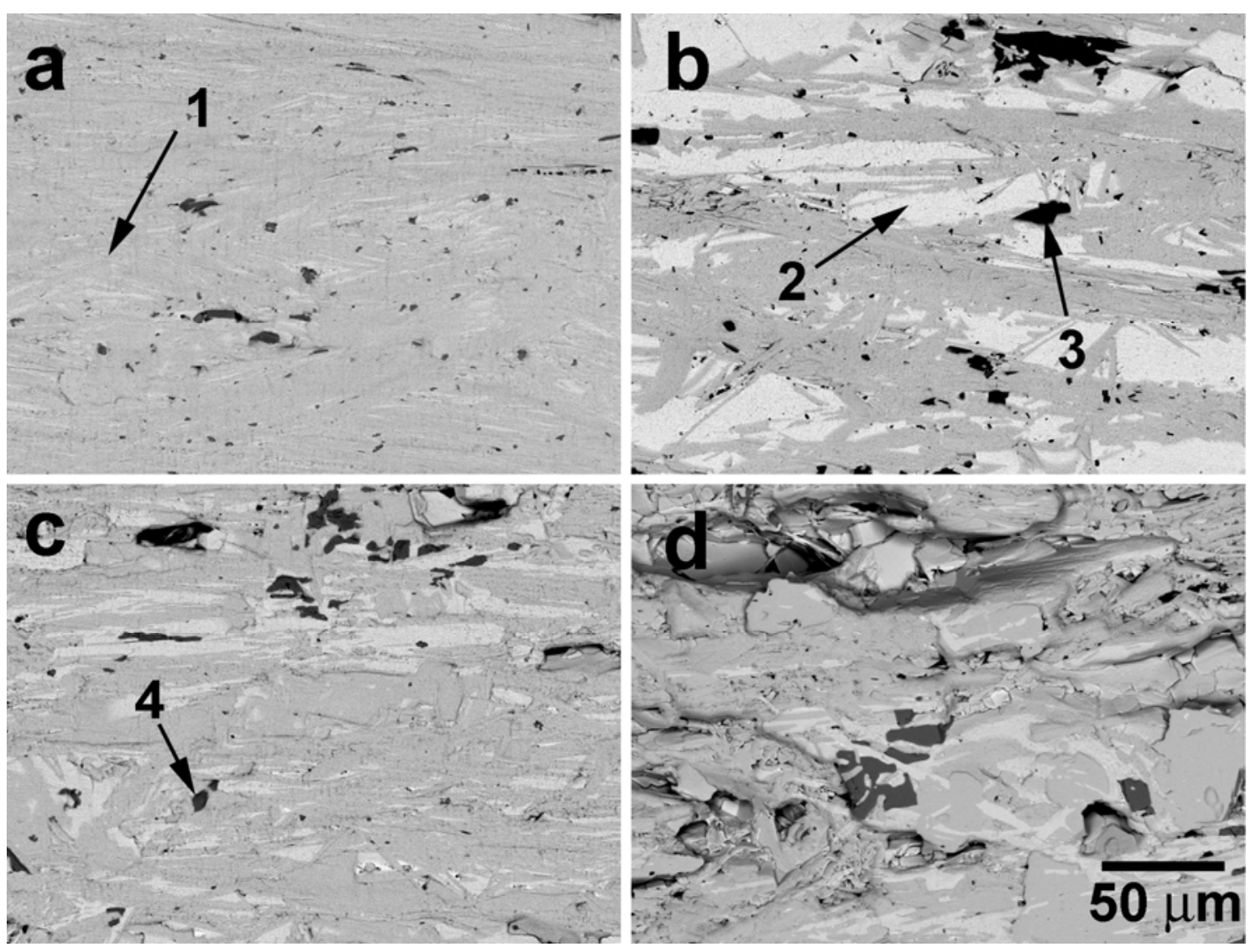


Figure 4

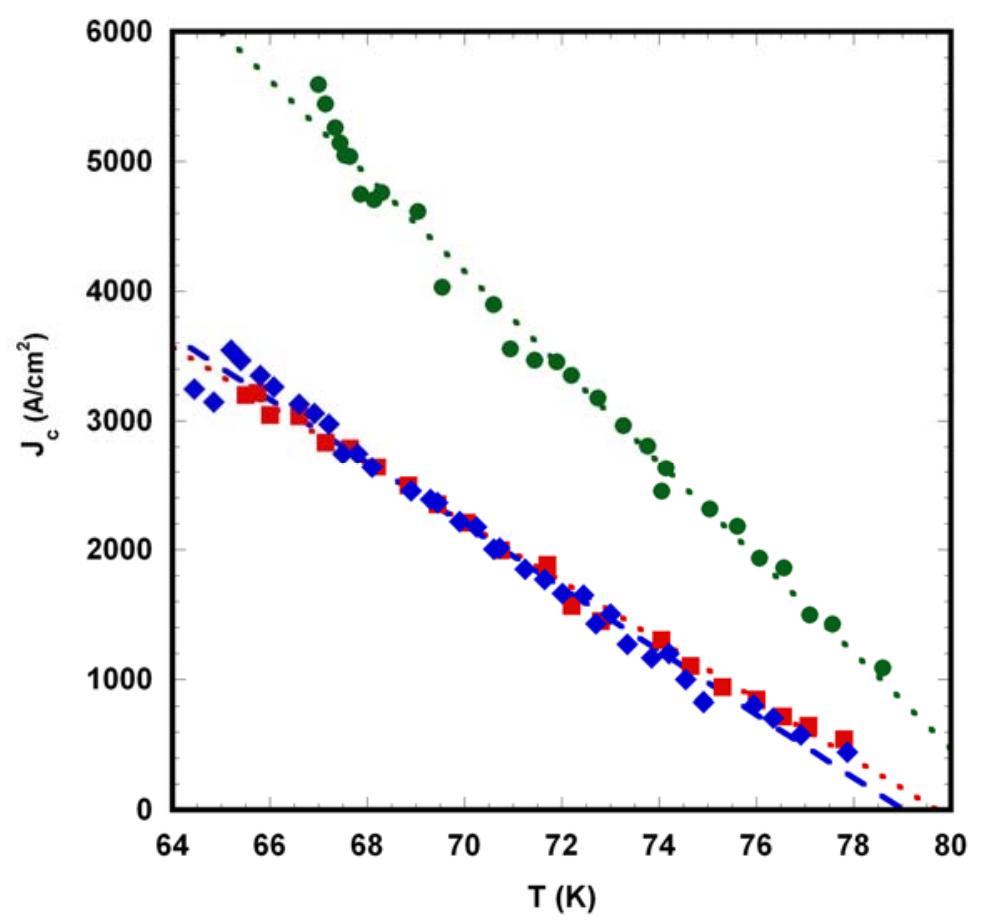


Figure 5

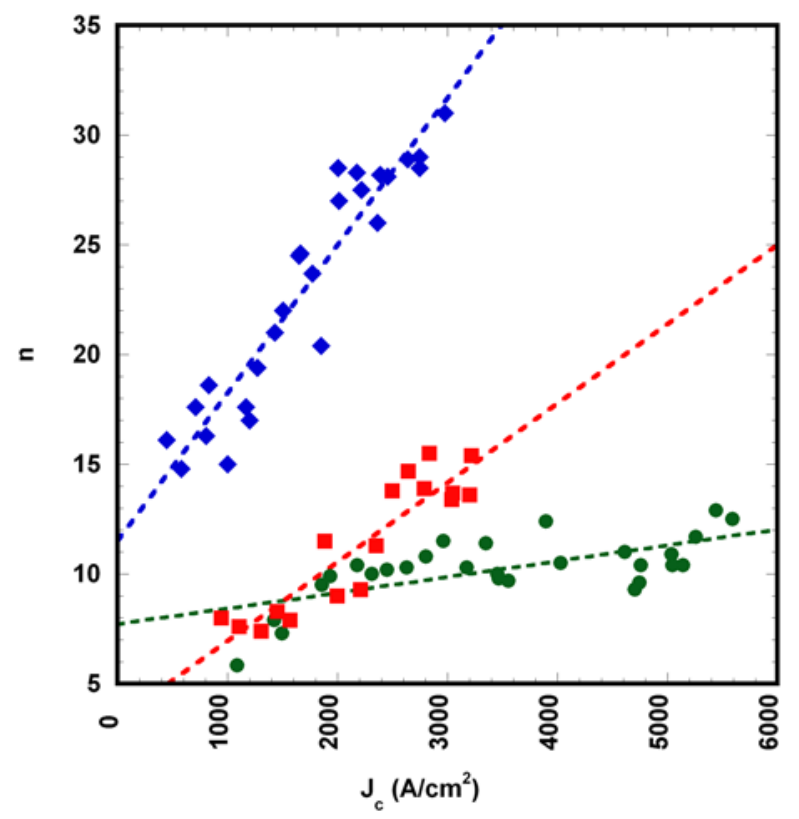

